\title{
The study of efficacy of injection iron sucrose in treatment of iron deficiency anemia in pregnancy
}

\author{
Akhileshwar Singh, Sanjay Singh*, Anuj Sharma
}

Department of Obstetrics and Gynaecology, Armed Forces Medical College, Pune, Maharashtra, India

Received: 08 April 2019

Accepted: 08 May 2019

\section{*Correspondence:}

Dr. Sanjay Singh,

E-mail: drsanjaysingh@gmail.com

Copyright: (C) the author(s), publisher and licensee Medip Academy. This is an open-access article distributed under the terms of the Creative Commons Attribution Non-Commercial License, which permits unrestricted non-commercial use, distribution, and reproduction in any medium, provided the original work is properly cited.

\begin{abstract}
Background: Iron deficiency is the most common cause of anaemia in pregnancy amounting to almost $50 \%$ of pregnant ladies in India. All pregnant women, irrespective of haemoglobin status, should receive prophylactic doses of iron from second trimester. Iron sucrose has an advantage of being cost effective and readily available. The objective of this was to study the efficacy of injection Iron Sucrose in treatment of iron deficiency anaemia in pregnancy.

Methods: About106 patients were given in injection iron sucrose in pregnancy, who had intolerance to oral iron or were non-compliant, in pre calculated (Ganzoni's formula) doses and were followed up with rise in hemoglobin and ferritin after 6 weeks and at term.

Results: Statistically significant increase in hemoglobin levels was observed at 6 weeks after initiation of treatment $(9.689 \pm 0.821 \mathrm{gm} \%$ vs $10.906 \pm 0.775 \mathrm{gm} \%)$ as well as at term (mean $10.981 \pm 0.690 \mathrm{gm} \%)$. The serum ferritin levels too increased significantly at term $(26.7 \mathrm{ng} / \mathrm{mL} \pm 12.92$ vs $65.34 \mathrm{ng} / \mathrm{mL} \pm 15.73)$.

Conclusions: Present study demonstrates that iron sucrose is an excellent option to treat iron deficiency anemia in patients where oral iron therapy has either failed or not suitable. It significantly increases hemoglobin levels in the study population. It is readily available in the market and can be infused on an outpatient basis.
\end{abstract}

Keywords: Ganzoni's formula, Iron deficiency anemia, Iron sucrose, Postpartum hemorrhage

\section{INTRODUCTION}

Iron is an important micronutrient in our human body where it is essential for various physiological processes as well as enzymatic reactions in order to sustain optimal immune, cognitive, mental and physical functions. Hence, iron deficiency anaemia, physiological or pathological, can cause derangement in various metabolic reactions resulting in adverse outcome.

Iron deficiency is the most common cause of anaemia in pregnancy amounting to almost $50 \%$ of pregnant ladies in India leading to various complications in pregnancy and postpartum period including preterm labor, antenatal and puerperal infections, postpartum haemorrhage, and sub involution of uterus, puerperal sepsis and rare but possible fetal growth restriction. ${ }^{1,2}$

All pregnant women, irrespective of haemoglobin status, should receive prophylactic doses of iron from second trimester. Those who develop anaemia should be promptly treated with oral or parenteral iron. Various parenteral iron preparations are available in the market, out of which the newer ones such as iron sucrose and ferric carboxylates are associated with less complication 
rates and anaphylactic reactions. Iron sucrose has an advantage of being cost effective and readily available. ${ }^{1,2}$

This study was conducted to study the efficacy of injection Iron Sucrose for the treatment of iron deficiency anemia in pregnancy who were given iron sucrose for non-compliance or intolerance to oral iron.

\section{METHODS}

Total 106 patients were included in the study. They were chosen to be given injection Iron Sucrose on the basis of intolerance or non-compliance to oral iron therapy or were deemed suitable by the clinician to be given iron sucrose and after confirmation of iron deficiency. All the patients were in their third trimester. Doses were calculated as per Ganzoni's formula mentioned below and various maternal outcomes were studied. Hemoglobin was checked after 6 weeks and before delivery. Serum ferritin was also checked before initiating the treatment and also at term.

\section{Inclusion criteria}

- All women attending antenatal clinic with hemoglobin $>7.5 \mathrm{gm} \%$ and $<11 \mathrm{gm} \%$ in third trimester

- Willing to follow up

\section{Exclusion criteria}

- Known hypersensitivity to parenteral iron therapy

- Anemia other than due to iron deficiency

- Chronic kidney disease

- Other chronic disorders (SLE etc.)

- Gastrointestinal disorders like Crohns' disease

- Unwilling to follow up

\section{Outcomes}

Rise in haemoglobin after 6 weeks and at term and rise in serum ferritin level at term.

\section{Dose calculation}

Dose was calculated as per Ganzoni's formula.

\section{Total iron deficit}

Dose in milligram $=2.4 \mathrm{x}$ body weight (kilogram) $\mathrm{X}$ (target haemoglobin-actual haemoglobin) + replenishment of iron stores, which was taken as $500 \mathrm{mg}$.

\section{Method of infusion}

- $200 \mathrm{mg}$ of iron sucrose was infused after diluting in $100 \mathrm{ml}$ of $0.9 \%$ normal saline,

- Infusion completed in 30 minutes,

- Total permissible dose in one day was $200 \mathrm{mg}$,
- Multiple doses were given on alternate days on outpatient basis,

- Minimum of 7 and maximum of 10 doses were given in one month,

- Sensitivity test was not done,

- Patients were kept under observation for one-hour post infusion for any reactions.

Place of study were a tertiary care hospital in Maharashtra. Duration of study were 8 months from $01^{\text {st }}$ Jun 2018 to $31^{\text {st }}$ Jan 2019.

\section{Statistical analysis}

Data analysis was performed by using SPSS (Statistical Package for Social Sciences) version 20:0. Qualitative data variables were expressed by using frequency and percentage (\%). Quantitative data variables were expressed by using Mean, SD etc. Paired t-test was used to find out the significance between pre-treatment and post-treatment values and P-value of $<0.05$ was considered as significant.

\section{RESULTS}

Total 106 anaemic pregnant mothers were given injection iron sucrose as per the discretion of the treating physician. The patients included were having haemoglobin between $>7.5 \mathrm{gm} \%$ to $<11 \mathrm{gm} \%$. All the patients were given iron sucrose after confirming iron deficiency as the cause of anaemia. These patients were followed up for their entire antenatal period and haemoglobin was checked pre-treatment and 6 weeks post-treatment and at term. Serum ferritin was also checked pre-treatment and at term. Following results were obtained.

Table 1 shows distribution of patients in terms of age and parity, who were enrolled for this study. Most of our patients were aged between 21 and 30 years (74.5\%). Primigravidae and multigravidae were almost equal in number $(48.1 \%$ and $58.9 \%$ respectively) enrolled in the study. The study population had co morbidities like gestational diabetes mellitus, gestational hypertension, history of previous cesarean and thyroid disorders and all of them were stable on medication.

Table 2 and Figure 1 show that rise in haemoglobin from before treatment (mean 9.689 $\pm 0.821 \mathrm{gm} \%$ ) to after treatment (mean $10.906 \pm 0.775 \mathrm{gm} \%$ ) was statistically significant ( $\mathrm{p}$-value $<0.001$ ) with mean increase in haemoglobin of $11.16 \% 6$ weeks after treatment. Table 2 and Figure 1 again show that haemoglobin rise at term (mean 10.981 $\pm 0.690 \mathrm{gm} \%$ ) was also significant (p-value $<0.001$ ) with mean increase in haemoglobin of $11.77 \%$ at term.

Table 3 and Figure 2 show that rise in ferritin levels from before treatment (mean $26.7 \mathrm{ng} / \mathrm{mL} \pm 12.92$ ) to ferritin levels at term (mean $65.34 \mathrm{ng} / \mathrm{mL} \pm 15.73$ ) was also 
significant (p-value $<0.001$ ) with mean increase in serum ferritin level of $59.14 \%$ at term.

Table 1: Demographic features and clinical characteristics of the study population.

\begin{tabular}{|c|c|c|c|}
\hline $\begin{array}{l}\text { Patient } \\
\text { variables }\end{array}$ & & $\begin{array}{l}\text { No. of } \\
\text { patients }\end{array}$ & $\%$ \\
\hline \multirow{4}{*}{ Age group } & $\leq 20$ & 21 & 19.8 \\
\hline & $21-25$ & 55 & 51.9 \\
\hline & $26-30$ & 24 & 22.6 \\
\hline & $>31$ & 6 & 5.7 \\
\hline \multirow{2}{*}{ Parity } & Primi & 51 & 48.1 \\
\hline & Multi & 55 & 51.9 \\
\hline \multirow{5}{*}{$\begin{array}{l}\text { Side } \\
\text { effects due } \\
\text { to iron } \\
\text { sucrose }\end{array}$} & Breathlessness & 3 & 2.8 \\
\hline & Headache & 1 & 0.9 \\
\hline & Local reaction & 5 & 4.7 \\
\hline & Nausea & 2 & 1.9 \\
\hline & Nil & 95 & 89.6 \\
\hline \multirow{7}{*}{$\begin{array}{l}\text { Co- } \\
\text { morbidities }\end{array}$} & Elderly & 3 & 2.8 \\
\hline & GDM & 2 & 1.9 \\
\hline & Hyperthyroidism & 1 & 0.9 \\
\hline & Hypothyroidism & 1 & 0.9 \\
\hline & $\mathrm{PIH}$ & 2 & 1.9 \\
\hline & $\begin{array}{l}\text { Previous } 1 \\
\text { LSCS }\end{array}$ & 10 & 9.4 \\
\hline & Previous 2 LSCS & 1 & 0.9 \\
\hline \multirow{4}{*}{ Medication } & $\begin{array}{l}\text { Eltroxin } 50 \mathrm{mcg} \\
\text { OD }\end{array}$ & 1 & 0.9 \\
\hline & $\begin{array}{l}\text { Medical nutrition } \\
\text { Therapy }\end{array}$ & 2 & 1.9 \\
\hline & $\begin{array}{l}\text { Neomercazole } 5 \\
\text { OD }\end{array}$ & 1 & 0.9 \\
\hline & Nil & 102 & 96.2 \\
\hline
\end{tabular}

Table 2: Rise in haemoglobin from before treatment to after treatment. Paired t-test used. P-value $<0.05$ (Significant).

\begin{tabular}{|lllll|}
\hline Hb at & $\begin{array}{l}\text { No. of } \\
\text { patients }\end{array}$ & \multicolumn{2}{l}{$\begin{array}{l}\text { Hemoglobin } \\
\text { (gm \%) }\end{array}$} & p-value \\
& Mean & SD & \\
\hline Before treatment & 106 & 9.689 & 0.821 & \\
\hline After treatment & 106 & 10.906 & 0.775 & $<0.001$ \\
\hline At term & 106 & 10.981 & 0.690 & $<0.001$ \\
\hline
\end{tabular}

Table 3: Rise in ferritin levels from before treatment to ferritin levels at term. Paired t-test used. P-value $<0.05$ (significant).

\begin{tabular}{|lllll|}
\cline { 1 - 3 } Ferritin & $\begin{array}{l}\text { No. of } \\
\text { patients }\end{array}$ & \multicolumn{2}{l}{ Ferritin $(\mathrm{ng} / \mathrm{mL})$} & p- \\
\cline { 1 - 4 } $\begin{array}{l}\text { Before } \\
\text { treatment }\end{array}$ & 106 & 26.70 & SD & value \\
\cline { 1 - 4 } At term & 106 & 65.34 & 15.73 & \\
\hline
\end{tabular}

Therefore, results of this study clearly demonstrate that Iron Sucrose is able to bring haemoglobin to optimum level at the time of delivery to cater for the anticipated blood loss of delivery and also for the postpartum needs of the mother.

\section{DISCUSSION}

Anemia in pregnancy is defined as hemoglobin levels of less than $11 \mathrm{gm} \%$ in venous blood irrespective of trimester (World health organization).(12)ICMR classifies anemia as mild (10-10.9 gm \%), moderate (7$9.9 \mathrm{gm} \%)$, severe (4-6.9 gm \%) and very severe $(<4$ gm\%). The above mentioned definition and classification are widely accepted in India. ${ }^{3}$

IDA has been the most common nutritional deficiency across the globe, with about 32 million pregnant women categorized as being anemic and about 0.75 million pregnant women categorized as being severely anaemic. ${ }^{4}$ India is one of those countries that have the highest prevalence of anemia in the world. According to the Indian national family health survey, the prevalence of IDA in pregnancy ranges from 23.6-61.4\%.5 The incidence of IDA in India was estimated at $60.0 \%$ in urban population and $69.0 \%$ in rural population, and IDA resulted in approximately 326,000 maternal deaths with an associated disability adjusted life years of 12,497,000. ${ }^{6}$ Diversity in cultures, religions, food habits, lifestyles, and traditions puts a challenge to the implementation of various government health programmed in India. It is assumed that low socio-economic status, high parity, nutritional deficiencies, phytate rich Indian diets, malaria, helminthic infections, and inflammatory or infectious diseases further increase the risks of IDA during pregnancy. ${ }^{7}$

Oral iron must be the preferred first-line treatment for iron deficiency. Women should receive information on improvement of dietary iron intake and factors affecting the absorption of dietary iron. Rich sources of dietary iron include red meat, fish and poultry. These provide haem iron that is more easily absorbed than non-haem iron, but the latter forms the vast majority of iron taken through the diet. ${ }^{8}$ Vitamin $\mathrm{C}$ enhances the absorption of non-haem iron; on the other hand, tea and coffee inhibit iron absorption from food.

Parenteral iron is indicated when oral iron is not tolerated or absorbed or patient compliance is in doubt or if the woman is approaching term and there is insufficient time for oral supplementation to be effective. ${ }^{7}$ Hence, parenteral iron could be an alternative to oral iron in patients who are unable to tolerate oral iron, and are noncompliant or need rapid restoration of iron stores. Parenteral iron can be used from the second trimester and during the postpartum period. ${ }^{9}$ Diagnosis of IDA has to be confirmed before starting parenteral therapy. Calculation of dose of parenteral Iron should be done before administration. The infusion has to be carried out 
only in a health facility with adequate supervision and availability for the management of anaphylaxis. ${ }^{10}$ Sensitivity test prior to infusion is highly recommended. Iron sucrose is most commonly used preparation for IV infusion and is safe with only a few adverse events. ${ }^{8}$ It is rapidly taken up by bone marrow for erythropoiesis and the reticulo-endothelial system for storage. The advantage of iron sucrose is that it doesn't require to administer a test dose and adverse reactions are virtually unknown. ${ }^{11}$ Intravenous iron sucrose was way more efficacious with few adverse effects than oral formulation in pregnant women with poor tolerability of oral iron and who required immediate replenishment of iron stores.

Neeru $\mathrm{S}$ et al, in a randomized control trial in 2012, used iron sucrose in comparison with oral iron for treatment of IDA and found that iron sucrose was effective in increasing hemoglobin significantly $(23.62 \%$ vs $14.11 \%$ in oral iron) with p-value $<0.05 .^{12}$ Bhavi SB et al, also reported a similar effect of iron sucrose in raising hemoglobin significantly ( $\mathrm{p}$-value $<0.0001) .{ }^{13}$ Qassim A et al, published a systematic review of 21 randomized controlled trials and 26 observational studies comparing injectable iron preparations irrespective of the comparator arms and proved that however parenteral preparations improve hematological parameters, but fail to alter maternal or perinatal outcomes. It also showed that none of the preparations are superior to each other; hence iron sucrose has a clear advantage of being cheaper and readily available. ${ }^{14}$

Dubey $\mathrm{S}$ et al, in a randomized trial used iron sucrose or oral iron in 200 pregnant patients and followed them up at 2,4 and then 4 weeklies till delivery. At all levels, it was shown that iron sucrose increased hemoglobin and iron stores faster than oral iron significantly ( $\mathrm{p}$-values of 0.000). ${ }^{15}$ Haldar $\mathrm{P}$ et al, retrospectively studied 990 pregnant patients who were given $400 \mathrm{mg}$ of intravenous iron sucrose at 2 primary health centers in rural India and found that mean increase of hemoglobin was $1.76 \mathrm{gm} \%$ and way higher (1.5times) in severely anemic patients. They recommended that dose of iron sucrose should be calculated as per Ganzoni's formula and dose be given accordingly as was done in this study. ${ }^{16}$ Present study supports the studies mentioned above and shows that iron sucrose is well tolerated as a parenteral iron preparation and has good outcomes in terms of increase in hemoglobin levels 6 weeks after treatment and term with a significant rise in serum ferritin levels which is more important to cater for the anticipated blood loss during delivery and lactational requirement.

\section{CONCLUSION}

Present study demonstrated that iron sucrose is an excellent option to treat iron deficiency anaemia in patients where oral iron therapy has either failed or not suitable. It significantly increases haemoglobin levels in the study population. It is readily available in the market and can be infused on an outpatient basis.
Funding: No funding sources

Conflict of interest: None declared

Ethical approval: Not required

\section{REFERENCES}

1. FOGSI general clinical practice recommendations. Available at: http:// www.fogsi.org/wpcontent/uploads/2017/07/gcpr-recommendationida.pdf.

2. Srilatha J. Prevalence of anemia in pregnant mothers and their outcome: a study in a semi urban area. Int $\mathbf{J}$ Reprod Contracept Obstet Gynecol. 2017;6:4886-9.

3. Good clinical practice recommendations for IDA in pregnancy in India $\mathbf{J}$ Obstet Gynaecol India. 2011;61(5):569-71.

4. Stevens GA, Finucane MM, Regil LM, Paciorek CJ, Flaxman SR, Branca F, et al. Nutrition impact model study group (anaemia). Global, regional, and national trends in hemoglobin concentration and prevalence of total and severe anemia in children and pregnant and non-pregnant women for 1995-2011: a systematic analysis of population-representative data. Lancet Glob Heal. 2013;1(1):e16-25.

5. Lokare PO. A study of prevalence of anemia and sociodemographic factors associated with anemia among pregnant women in Aurangabad city, India. Annals Nigerian Med. 2012;6(1):30-4.

6. Toteja GS, Singh P, Dhillon BS, Saxena BN, Ahmed FU, Singh RP, et al. Prevalence of anemia among pregnant women and adolescent girls in 16 districts of India. Food Nutri Bullet. 2006;27(4):311-5.

7. RCOG green-top guideline No.47. Available at: https://www.rcog.org.uk / globalassets / documents / guidelines / gtg-47.pdf.

8. Lynch SR. Interaction of iron with other nutrients. Nutr Rev. 1997;55:102.

9. Pavord S, Myers B, Robinson S, Allard S, Strong J, Oppenheime C. UK guidelines on the management of iron deficiency in pregnancy. British committee for standards in haematology. Brit Soc Haematol. 2012;156:588-600.

10. Rampton D, Folkersen J, Fishbane S, Hedenus M, Howaldt S, Locatelli F, et al. Hypersensitivity reactions to intravenous iron: guidance for risk minimization and management. Haematol. 2014;99(11):1671-6.

11. Shi Q, Leng W, Wazir R, Li J, Yao Q, Mi C, et al. Intravenous iron sucrose versus oral iron in the treatment of pregnancy with iron deficiency anaemia: a systematic review. Gynecol Obstetr Invest. 2015;80(3):170-8.

12. Neeru S, Nair NS, Rai L. Iron sucrose versus oral iron therapy in pregnancy anemia. Indian $\mathrm{J}$ Comm Med. 2012;37(4):214-8.

13. Bhavi SB, Jaju PB. Intravenous iron sucrose v/s oral ferrous fumarate for treatment of anemia in pregnancy. A randomized controlled trial. BMC Preg Childbirth. 2017;17(1):137. 
14. Qassim A, Mol BW, Grivell RM, Grzeskowiak LE. Safety and efficacy of intravenous iron polymaltose, iron sucrose and ferriccarboxymaltose in pregnancy: a systematic review. NZJ Obstet Gynaecol. 2018;58:22-39.

15. Dubey S, Suri V, Aggarawal N, Das R. Is it safe to use intravenous iron sucrose during pregnancy? a randomized controlled trial. Int J Reprod Contracept Obstet Gynecol. 2013;2:544-9.

16. Haldar P, Kant S, Yadav V, Majhi J, Malhotra S, Kaur R, et al. Effect of intravenous iron sucrose on hemoglobin level, when administered in a standarddose, to anemic pregnant women in rural Northern India. J Family Med Prim Care. 2018;7:762-8.

Cite this article as: Singh $\mathrm{A}$, Singh S, Sharma A. The study of efficacy of injection iron sucrose in treatment of iron deficiency anemia in pregnancy. Int J Reprod Contracept Obstet Gynecol 2019;8:2444-8. 